\title{
Refractory Laryngeal Squamous Cell Carcinoma
}

National Cancer Institute

\section{Source}

National Cancer Institute. Refractory Laryngeal Squamous Cell Carcinoma. NCI

Thesaurus. Code C148383.

Laryngeal squamous cell carcinoma that does not respond to treatment. 